\title{
Questionando o saber refletindo sobre o fazer: inquietações de professores sobre a profissionalidade docente universitária
}

\author{
Kátia Maria da Cruz Ramos*
}

\section{Resumo}

Este trabalho transita pelo movimento de reconceitualização da docência universitária e tem como propósito trazer elementos para o recente debate sobre essa profissionalidade, no contexto da compreensão da docência como uma profissão de relaçóes. Para tanto, congrega dados de uma década de envolvimento em ações de atualização didático-pedagógica, endereçadas a professores universitários, estabelecendo diálogo com estudos que têm como base um olhar multirreferencial no quadro da compreensão e defesa de uma profissionalidade docente reflexiva, investigativa e crítica, baseada numa ética de responsabilidade individual e coletiva. Neste sentido, delineia caminhos que vêm possibilitando a professores universitários uma ressignificação da função docente, no contexto da compreensão de que questionar o saber e refletir sobre o fazer é movimento inerente à docência em geral e dinâmica estruturante da profissionalidade docente universitária em particular.

Palavras-chave: Profissionalidade docente universitária. Docência universitária. Formação docente.

* Doutora em Ciências da Educação pela Universidade do Porto, Portugal. Professora do Programa de Pós-Graduação em Educação e do Departamento de Métodos e Técnicas de Ensino da Universidade Federal de Pernambuco (UFPE), membro do Núcleo de Formação Continuada Didático-Pedagógica dos Professores da UFPE (NUFOPE) e membro colaborador do Centro de Investigaçáo e Intervençáo Educativas (CIIE) da Universidade do Porto (U.Porto). 


\section{Introdução}

O debate sobre a profissionalidade docente vem ganhando espaço, nomeadamente no que diz respeito ao conhecimento formador em confronto com saberes mobilizados neste exercício, no âmbito da afirmação da docência como uma profissão de relações. Neste contexto, a função de ensinar definida apenas pelo domínio de um conhecimento disciplinar é questionada pela compreensão de que ensinar é uma função complexa que se alicerça em saberes próprios - (re)construídos em diálogo com uma multiplicidade de conhecimentos, saberes e fazeres.

Tal debate tem contribuído para o reconhecimento da condição profissional da atividade docente, repercutindo, mesmo que em escala ainda incipiente, no âmbito da docência universitária em razão de sua explícita responsabilidade no processo de aprendizagem do estudante. Surge, entre outros fatores, em decorrência de questionamentos ao conhecimento universitário de característica disciplinar, de estudos que vêm tomando essa temática como objeto de reflexão, e em função de inquietaçōes de professores sobre a profissionalidade docente universitária.

É a partir desta ideia que trago neste trabalho questóes relacionadas à profissionalidade docente universitária, sem descurar de estudos que alertam para o movimento de massificação e mercantilização do ensino superior, mas buscando apoio em trabalhos que visam superar tal movimento afirmando a responsabilidade social da universidade.

Para tanto, centro a atenção na temática da profissionalidade docente iniciando por situar um movimento de reconceitualização da docência no âmbito de uma redefiniçấo da Universidade no ensino superior, no sentido de trazer elementos para o recente debate sobre a profissionalidade docente universitária. De posse desses elementos, caracterizo um movimento de atenção a questóes de ordem didático-pedagógica desenvolvido na Universidade Federal de Pernambuco (UFPE), desde 2000 até a presente data, ${ }^{1}$ e um movimento desencadeado na Universidade do Porto (U.Porto), em 2005, e por mim acompanhado até o início de 2008. Desses dois movimentos, trago inquietaçóes de professores sobre a profissionalidade docente universitária. Inquietaçôes que, no espaço de açôes de atualização didático-pedagógica, possibilitaram ressignificar a função docente universitária num contexto de partilha de saberes e de fazeres - ao servirem 
de suporte para questionar o saber refletindo sobre o fazer, no sentido da compreensão da dinâmica que caracteriza a profissionalidade docente universitária em sua complexidade e singularidade.

\section{Um movimento de reconceitualização da docência universitária}

Ao longo da sua história, a Universidade enfrentou, segundo Wittrock (1996), dois períodos críticos anteriores ao século XX - o primeiro, relacionado com a crise do Renascimento, e o segundo, no surgimento da Universidade Moderna. No que respeita a esse segundo período, Rocha (2002) ressalta a revolução causada pelo livro impresso e destaca a ideia de Humboldt de relacionar ensino e investigação, como uma forma de resguardar a Universidade diante de tal revolução.

Em meados do século XX, a estabilidade institucional da Universidade volta a ser abalada, sendo tal situação interpretada por Santos (1996) como o despreparo da Universidade para lidar com desafios postos pela sociedade e pelo Estado. E, situando esse abalo numa transição da relação entre conhecimento, universidade e sociedade, Barnett (2001, p.19) considera-o como "um processo no qual a universidade está deixando as margens da sociedade para incorporar-se a ela". Tal ordem de acontecimento veio revelar o que Santos (2004) denomina "irresponsabilidade social da Universidade" e provocar uma tomada de posição diante de uma necessária incorporação na dinâmica social, principalmente em razão de uma lógica de produzir conhecimento radicalmente contrária ao paradigma da racionalidade científica tradicional (GIBBONS et al., 1994).

Ampliando a interpretação desta situação, Bourdoncle e Lessard (2002, p. 151), considerando uma mudança na relação da universidade com a sociedade, evidenciam que a Universidade "já não pode limitar-se a dar uma formação geral e liberal, nem uma formação científica, ignorando a maneira como os estudantes poderão depois ganhar a sua vida”.

Nesta perspectiva, Santos (2004, p. 40) aponta para uma necessária ruptura com o conhecimento universitário convencional, considerado "predominantemente disciplinar cuja autonomia impôs um processo de produção relativamente descontextualizado em relação às premências do quotidiano das sociedades". E ressalta a pertinência da assunção 
da responsabilidade social da Universidade, através da produção do conhecimento pluriversitário que é "contextual na medida em que o princípio organizador da sua produção é a aplicação que lhe pode ser dada" (SANTOS, 2004, p. 41).

Neste sentido, o resgate do princípio de indissociabilidade entre ensino (formação graduada e pós-graduada), investigação e prestação de serviço à comunidade exige que tais atividades sejam efetivadas de forma articulada. Nomeadamente, diante do reconhecimento da articulaçáo dessas atividades como marca singular da docência universitária, no contexto da compreensão da mediação didática como função que dá o tom à profissionalidade docente e da especificidade que esta mediaçáo assume ao ser compreendida como espaço privilegiado de (re)produção, (re)configuração e (re)criação de conhecimentos, fazeres e saberes.

É nessa compreensão que a docência universitária, principalmente na transiçấo do século XX para o século XXI, tem vindo a ser evidenciada e reconhecida como necessária e de importância fundamental para o desenvolvimento da Educaçáo Superior. Entre outras razóes, em decorrência do debate instalado a partir da "Declaraçấo Mundial sobre a Educação Superior no Século XXI: visão e ação" (UNESCO, 1998), e de reflexões oriundas de estudos que vêm tomando essa temática como objeto de análise, no sentido de reconhecimento da docência como uma açáo complexa que requer saberes específicos, decorrentes de uma condição profissional docente "de saber justificar as açôes desenvolvidas, recorrendo a uma base de conhecimentos fundamentados, a uma argumentação teoricamente sustentada" (CUNHA, 2007, p. 22). No sentido de superar a visão de que quem sabe, automaticamente sabe ensinar, e a de que só quem sabe investigar, pode realmente ensinar ${ }^{2}$.

Tal atenção à docência universitária (embora ainda não se disponham de registros que indiquem sua amplitude) decorre também de uma demanda dos docentes por um conhecimento que lhes permita ultrapassar uma situação de despreparo para o exercício docente. Fato este também reconhecido por Bazzo (2007) como indicativo de um movimento de busca de suporte para uma reconfiguraçấo de saberes e de fazeres no contexto da docência universitária.

Tal compreensão revela um movimento de reconceitualizaçáo da docência universitária, no contexto da justificação da Universidade 
no limiar do século XXI, tanto reconhecendo a docência, conforme Cunha (1998, p. 15), por excelência articuladora "do paradigma de ensinar e de aprender na universidade", como abrindo caminhos para o reconhecimento e delineamento do estatuto de uma profissionalidade docente universitária.

\section{Profissionalidade Docente Universitária: um debate em construção}

Reconhecendo a insuficiência de uma profissionalidade docente centrada no domínio disciplinar, o movimento de reconceitualização da docência universitária em tela instala um debate sobre esta profissionalidade, situando-a como uma profissão de interaçóes humanas - no sentido tanto de uma revisão do seu caráter como de delineamento de elementos estruturantes da profissionalidade em questáo, nomeadamente através do campo em construção da Pedagogia Universitária. Neste contexto, a produçâo sobre essa docência tem como um de seus eixos a compreensão de docência como "um trabalho cujo objeto não é constituído de matéria inerte ou de símbolos, mas de relaçôes humanas com pessoas capazes de iniciativa e dotadas de uma certa capacidade de resistir ou de participar da açáo dos professores" (TARDIF; LESSARD, 2005, p. 35).

No âmbito da instalação desse debate, vêm sendo desenvolvidas reflexóes que assumem o campo da Pedagogia Universitária como como foco, tendo por exemplo, entre outros, os estudos de Engers e Morosini (2007), Franco e Krahe (2007), Broilo e Cunha (2008), Cordeiro e Melo (2008), Leite (2010) e Vieira (2010), que buscam possibilitar uma maior visibilidade e compreensão do sentido uno e diverso que caracteriza a docência universitária.

Ainda objetivando tratar da docência universitária no contexto da sua complexidade, vêm sendo desenvolvidos estudos em rede buscando, para além de um intercâmbio e uma interlocução, uma partilha de construção e de socialização de conhecimentos. Neste âmbito, destaca-se a Rede Sulbrasileira de Investigadores da Educação Superior (RIES), que tem investido na produção e divulgação de conhecimento acerca desta temática, através de investigaçôes interinstitucionais, congressos, seminários e publicaçôes. E, com o propósito de ampliar estudo em rede, está em processo de construção 
a Rede Inter-Regional N-NE-CO de Docência na Educação Superior (RIDES).

Um ponto a destacar é o fato de que a RIES tem também estreitado o diálogo com outras instituições estrangeiras, a exemplo da Universidade de Aveiro, Universidade de Buenos Aires, Universidade de Lisboa e Universidade do Porto. No que diz respeito à Universidade de Aveiro, no âmbito do Laboratório de Estudo e Intervenção no Ensino Superior (LEIES), foi criada a rede Docência, Aprendizagem, Desenvolvimento e Avaliação no Ensino Superior (DADAES) e o espaço de divulgação on-line denominado Docência e Aprendizagem no Ensino Superior (d@es).

Tomando como referência reflexóes oriundas desses estudos, ressalto que tratar da questão da profissionalidade docente universitária exige considerar o desafio de lidar com um conceito em construção, tanto no âmbito do conceito de profissionalidade docente como do conceito de docência universitária, no quadro de uma condição profissional.

Por tal razão, recorro a autores que tratam da noção de profissionalidade em geral, iniciando por duas concepçóes de profissionalidade apresentadas por Dubar (1987, p. 7) - nomeadamente no contexto de uma relação entre qualificação e competência. Este autor define competência "como qualidades pessoais provenientes da experiência e da personalidade, e fator duma profissionalidade de tipo empírico", e a questão da qualificação como "qualificação jurídica atestada e hierarquizada pelos títulos escolares, e garantia duma profissionalidade de tipo científico" (DUBAR, 1987, p. 7). Indo além dessa compreensão, Braem (2000, p. 24) identifica uma íntima relação entre qualificação e competência, afirmando que "a profissionalidade inclui a qualificação e a competência (e assim o coletivo e o individual)”.

Seguindo a linha de estabelecimento de uma relação entre competência e qualificação, Demailly (1987) ressalta a importância da qualificação evidenciando a implicação do desenvolvimento das competências para o exercício docente, no sentido de possibilitarem práticas interventivas.

Nesta perspectiva, a profissionalidade congrega qualificação e competência que, apesar de distintas, respeitam a um mesmo movimento relacional. Ou seja, conforme Bourdoncle (1991, p. 76), "a profissionalidade vai remeter para a natureza mais ou menos elevada e racionalizada dos conhecimentos e das capacidades utilizados no exercício profissional". 
Tal compreensão evidencia a pertinência de Ramalho, Nuñez e Gauthier (2004) considerarem profissionalidade como estado e processo. Neste sentido, o conceito de profissionalidade docente diz respeito ao que Gimeno Sacristán (1995, p. 65) aponta como "a afirmação do que é específico na acção docente".

Detendo-se na situação específica dos docentes de ensino superior, Roldão (2005) tece uma análise acerca do poder desses docentes sobre a ação, ressaltando que, apesar de tal poder, o exercício docente no ensino superior continua marcado pela concepção de ensino como mera transmissão. Em razão deste fato, a autora aponta para a pertinência do processo de ressignificar o sentido de ensinar, no quadro de superar a visão do professor enquanto profissional de um saber - neste caso o que identificaria a profissionalidade do docente seria o saber a ser ensinado (ROLDÁO, 2005). E acrescenta que ressignificar o sentido de ensinar diz respeito a considerar o professor como um profissional de ensino, na perspectiva de reforçar o estatuto da profissionalidade docente "porque a função de ensinar, assim entendida, é alguma coisa que lhe é específica, que outros actores, se possuírem saberes apenas conteudinais idênticos, não saberão fazer" (ROLDÃO, 2005, p. 117).

Neste contexto, importa considerar a ideia de Zabalza (2004, p. 145) de que a docência universitária "requer uma sólida formação, não apenas nos conteúdos científicos próprios da disciplina, como também nos aspectos correspondentes a sua didática e ao encaminhamento das diversas variáveis que caracterizam a docência”.

Extrapolando a questão mais imediata da profissionalidade docente universitária, Cunha e Leite (1996, p. 81) apontam que "os rituais acadêmicos estão fundamentalmente ligados à estrutura de poder da sociedade e, como capital cultural, variam de acordo com o tipo de fazer profissional presente na organização social do trabalho". Esta compreensão impossibilita pensar numa pedagogia universitária única, mas não inviabiliza considerar questóes presentes e desafios que afetam a docência universitária, no que diz respeito a aspectos comuns no contexto da complexidade e diversidade desta docência.

Situando um desses desafios, Cunha (1998, p. 23) aponta para a questão dos conhecimentos legitimados para o exercício docente universitário, destacando a importância da Pedagogia Universitária como "campo de 
produção de conhecimentos e dos saberes docentes”. Nomeadamente, tendo em conta que os critérios de inserção na carreira universitária ainda privilegiam o domínio de um campo disciplinar, colocando esse aspecto como dimensão única e qualificação necessária. Fato que, no contexto do movimento de reconceitualização da docência universitária, vem desafiando o delineamento de elementos estruturantes da profissionalidade docente universitária no contexto da relação qualificação-competência - através do reconhecimento da pertinência da reflexão didático-político-pedagógica na Universidade.

A partir desses pontos, retomo uma concepção de Universidade, que em outro lugar afirmei "como locus de reprodução, reconfiguração e criação de conhecimentos, ideias e valores - num contexto de incentivo à dúvida e assunção da incerteza" (RAMOS, 2008, p. 34), bem como a compreensão do princípio de indissociabilidade como estruturante da dinâmica de criação, difusão e produção do conhecimento, para situar o debate em construção sobre a profissionalidade docente universitária, o qual vem apontando para o caráter mediador do conhecimento didático-pedagógico no processo de reafirmação da marca identitária da Universidade no contexto da Educação Superior.

É neste sentido que me proponho a tratar de ações de atualização didático-pedagógica como espaço de reflexão sobre a profissionalidade docente universitária, objetivadas para contribuir no processo de desconstruçáo do docente como profissional de um saber, fornecendo elementos estruturantes para que os docentes se compreendam e se assumam como profissionais de ensino - no contexto do diálogo do uno-diverso, pessoal-profissional e individual-coletivo.

\section{Profissionalidade docente universitária: questionando o saber refletindo sobre o fazer}

Sem perder de vista questóes mais amplas presentes na (re)configuração da Universidade, e ciente da complexidade que caracteriza a profissionalidade docente universitária, a razão de trazer duas experiências de atenção a questôes de ordem didático-pedagógica tem como propósito caracterizar processos de ressignificação da função docente universitária - no contexto do desafio de dialogar com inquietaçóes que questionam o saber refletindo 
sobre o fazer.

A primeira experiência, desenvolvida na Universidade Federal de Pernambuco (UFPE), situa-se no âmbito do Núcleo de Formação Continuada Didático-Pedagógica dos Professores da UFPE (NUFOPE). Este Núcleo, embora inaugurado em 2008, resulta de um processo que data do ano de 2000, desencadeado com o Projeto de Atualização DidáticoPedagógico para Professores da UFPE, nomeadamente em função da avaliação do trabalho desenvolvido que apontou para a necessidade de ampliação das atividades e criação de condiçóes para um acompanhamento sistemático dos processos de formação continuada didático-pedagógica nesta Universidade.

O NUFOPE tem como objeto a docência no contexto da Universidade no que diz respeito a sistematizar processos reflexivos acerca da profissionalidade docente universitária. E como eixo, uma concepção de formaçáo continuada centrada na profissionalizaçâo docente como um permanente processo de construção/desconstrução/reconstrução (UFPE, 2008). A equipe do NUFOPE está composta por sete professores ${ }^{3}$, os quais, por sua vez, desenvolvem atividades de coordenação de ações de formação, estudo, pesquisa e publicação no âmbito de temáticas relacionadas com a docência universitária. Essa equipe tem um horário semanal destinado às atividades ordinárias do Núcleo (colegiado, estudo, atendimento).

Esse Núcleo elegeu a formação didático-pedagógica como objeto de investigação e intervenção, desenvolvendo atividades que possibilitem sistematizar, entre outros, estudos e reflexóes emergentes na e para essa formação, sendo uma frequência acima de 50\% condição para o docente participar das açóes oferecidas pelo NUFOPE.

Inicialmente, as ações de formação didático-pedagógica eram oferecidas em uma única etapa, de forma pontual, congregando 21 horas de atividades e atendendo a vinte e cinco professores por turma. Em razão do reconhecimento do limite desta intervenção, decorrente de solicitaçóes para ampliação da carga horária no quadro da necessidade de possibilitar uma reflexão mais consistente, conservou-se o número de professores por turma e alterou-se o formato para dois módulos congregando 45 horas, sendo o primeiro voltado para questóes da Universidade e da docência em geral (21 horas), e o segundo, para a aula universitária em particular, tendo como eixo uma reflexão sobre a própria experiência docente (24 horas). 
Vêm sendo oferecidas também ações voltadas para Educação a Distância, congregando 10 horas de atividades.

A divulgação das ações conta com o apoio da Pró-Reitoria para Assuntos Acadêmicos (PROACAd) e da direção do Centro de Educação (CE) da UFPE, sendo feita através de mala direta, na homepage desta PróReitoria e Centro - para além da afixação de cartazes nos Departamentos e locais de grande circulação na UFPE. Neste aspecto, a questão da docência é encarada como também de responsabilidade institucional. Isso, sem contar com a divulgação que é feita pelos professores que participaram de açôes anteriores e incentivam os colegas a também participarem, tanto pelo reconhecido contributo da intervenção como pelo fato da certificação contar no memorial de progressão na carreira.

Compreendendo a docência como uma profissão de relaçóes, a equipe do NUFOPE sistematicamente faz reflexôes questionando o saber refletindo sobre o fazer, tanto no desenvolvimento das atividades ordinárias como no contexto do desenvolvimento de ações de formação. E é com esse propósito que realiza as açóes em tela, buscando dialogar com inquietaçóes de professores universitários sobre profissionalidade docente universitária.

A segunda experiência, desenvolvida na Universidade do Porto (U. Porto) no âmbito do Grupo de Investigação e Intervenção Pedagógica da Universidade do Porto (GIIPUP), refere-se ao acompanhamento de açóes de formação didático-pedagógica, no período de 2005 a 2008. E situa-se numa investigação objetivada para analisar possibilidades de ações de formação didático-pedagógica que se configurem como um espaço de reflexão sobre a profissionalidade docente universitária.

As ações consideradas têm como ponto de partida uma preocupação da Reitoria da Universidade do Porto em intervir em níveis que permitissem melhorar a qualidade do funcionamento dos cursos naquela universidade, no contexto da ideia da necessidade da preparação didático-pedagógica dos docentes. A primeira delas foi a Acção Piloto de Actualizaçâo PedagógicoDidáctica de Docentes da Universidade do Porto, que desencadeou um movimento de institucionalização de atenção a questões de ordem didáticopedagógica na referida instituição.

Para essa ação foram disponibilizadas vinte e cinco vagas, congregando 20 horas de atividades e contemplando as seguintes temáticas: "O ensino e a aprendizagem numa formação universitária”; "Jovens e adultos em 
desenvolvimento e a relação de formação na Universidade"; "A avaliação da aprendizagem no ensino universitário"; "A componente on-line no Ensino Superior"; "A docência universitária face aos desafios sociais e da sociedade do conhecimento".

A Acção Piloto extrapolou as expectativas dos docentes envolvidos e criou o desejo de continuar o debate instalado. Neste sentido, essa ação inaugura uma fase na U.Porto tanto ao requerer uma responsabilidade institucional para com a docência universitária como ao possibilitar constituir um grupo institucional de investigação e intervenção. Tal grupo, denominado Grupo de Intervenção e Investigação Pedagógica da Universidade do Porto (GIIPUP), constituiu-se com o principal objetivo de promover processos de valorizaçáo da dimensão pedagógica da docência na U.Porto - estruturando um plano de trabalho em torno do desenvolvimento de investigaçóes e da partilha/ disseminação das práticas de ensino-aprendizagem.

O GIIPUP, no período em evidência, contou com o apoio da Reitoria, da Faculdade de Engenharia (FE), Faculdade de Psicologia e de Ciências da Educação (FPCE), do Centro de Investigação e Intervenção Educativas (CIIE) e do Centro de Educação Médica (CEM) da U.Porto, sendo as açôes divulgadas através de mala direta, na home do GIIPUP e por professores que participaram de açóes anteriores.

As ações de formação desenvolvidas no contexto do GIIPUP tiveram diversos formatos, tendo como eixo a partilha de saberes e fazeres, realizadas inicialmente na perspectiva de reflexão do próprio Grupo para, posteriormente, caracterizar-se como encontros pontuais, em função de uma dispersão dos envolvidos por conta da demanda de trabalho nas áreas de origem e da elaboração de um projeto de pesquisa para financiar as atividades do próprio GIIPUP. Mas sempre fiel ao propósito de desencadear reflexões sobre o saber-fazer.

Apesar de terem pontos distintos, as duas experiências em tela, desenvolvida na UFPE e na U. Porto, têm pontos em comum no que diz respeito à condução teórico-metodológica e à clientela que vai em busca de ações de ordem didático-pedagógico. Esta última, tanto no que se refere às características do docente como a inquietaçóes explicitadas.

Embora as duas experiências tenham recebido docentes com tempo de serviço variando de um a mais de trinta anos, uma característica marcante 
foi a incidência de professores que assumiram a docência como primeiro emprego. Em muitos casos, foram iniciados na docência através de Iniciação Científica e Monitoria. Ou optaram pela docência universitária como forma de continuar a desenvolver atividades relacionadas à investigação. Em alguns casos, ingressaram na docência por ser esta uma considerável oportunidade de emprego, na relação salário-carga de trabalho.

No âmbito das inquietações apresentadas pelos envolvidos nas experiências em tela, destaco três para compor este trabalho. A primeira inquietação contemplada residia na procura dos professores por um conhecimento que ensine a ensinar, para fazer o estudante aprender isso tanto na lógica da indicação de um método para tal fim como no reconhecimento da função docente como recurso privilegiado na mediação didática. No contexto dessas experiências, o grupo que solicitava a indicação de um método demonstrava confusão quando lhe era requerido refletir sobre a docência como um ofício feito de saberes (GAUTHIER et al., 1998). E o grupo que reconhece a função docente como recurso privilegiado expóe o desejo de sistematizar um processo de questionar o saber refletindo sobre o fazer, supervisionado por quem coordenava a ação de formação.

Uma segunda inquietação dizia respeito à necessidade de justificar o que se faz e dá certo, no sentido de fundamentar o saber justificando o fazer. Este fato pode ser decorrente do desencadeamento de uma reflexão sobre o fazer no quadro da constação de referenciais limitados para questionar o saber. Tal inquietaçáo mobilizava os professores a solicitar referencial teórico para auxiliar nesse processo, representando uma surpresa diante da dinâmica da profissionalidade docente bem como do seu caráter multidimensional.

A terceira inquietação contemplada dizia respeito ao fato dos professores acreditarem que são os únicos a terem problemas na sala de aula. Essa inquietação foi visivelmente tranquilizada no momento da socialização das experiências dos envolvidos, nitidamente contribuindo para o reconhecimento da pertinência do trabalho coletivo bem como da troca de experiências.

Essas são inquietaçóes que, ao longo de uma década de envolvimento em ações de atualização didático-pedagógica, vêm sendo apresentadas como elemento mobilizador para procura por tais processos formativos, expressando um desejo, conforme Leite e Ramos (2007), de saber ensinar 
para fazer aprender, cuja direção é encontrar respostas para uma questão fundamental: o que preciso aprender para saber ensinar?

Neste sentido, considerando a afirmação de Cunha (2006, p. 80) de que "os saberes constitutivos da profissão docente implicam consciência, compreensão e conhecimento", questionar o saber refletindo sobre o fazer é tarefa ordinária do docente universitário - tanto em função da dinâmica inerente à profissionalidade docente como em razão do príncipio de indissociabilidade que atribui a essa docência a condição de elemento base de uma Educação Superior.

\section{Considerações finais}

Diante do exposto, o fato das açóes terem por base uma contextualização da prática pedagógica docente, contemplando a questão da docência no contexto da Universidade, vem contribuindo para os docentes situarem a dinâmica relacional qualificação-competência, inerente à profissionalidade docente. Isso acontece, principalmente em razão do desencadear de uma reflexão sobre a própria construção docente e do estímulo que tem representado, nas duas instituições consideradas, eleger a participação em ações de formação didático-pedagógica como parte da carreira docente universitária. Fato este que vem contribuindo para uma ressignificação da docência universitária, através da (re)construção de saberes e (re) reconfiguração de fazeres no âmbito desta profissionalidade docente.

Neste quadro, questóes relacionadas a "ser Professor universitário", juntamente com reflexôes sobre o efetivo exercício docente, vêm possibilitando desconstruir a concepção de docente como profissional de um saber e a assunção do docente como um profissional de ensino (ROLDÃO, 2005). E as experiências em tela também têm contribuído para evidenciar, tal qual em outro lugar afirmei, que é imprescindível que se prime pelo rigor nas reflexóes desta ordem, no sentido de ter um conhecimento balizador que dê suporte ao diálogo com os saberes experienciais (RAMOS, 2010). Ao mesmo tempo em que enfrentar o desafio de romper com a visão de docência como transmissão inicia-se no contexto da própria açâo, desencadeando um processo de ressignificação da relação ensino-aprendizagem, ao eliminar a existência de um dador e de um recebedor (RIOS, 2008). Ou seja, contrária à lógica de que uma pessoa ensina e uma outra aprende, questionar o saber 
refletindo sobre o fazer é uma via de mão dupla, onde a (re)configuração de saberes e de fazeres é tarefa de cada um e responsabilidade de todos.

\section{Notas}

1 Setembro/2010.

2 Esta visão decorre da proposição de união entre o ensino e a investigação que, conforme Bordouncle e Lessard (2002, p. 139), considera que o melhor professor é por definição o melhor investigador.

3 Três desses sete componentes, incluindo eu mesma, vêm acompanhando o processo desde a elaboração do Projeto de Atualização DidáticoPedagógica para Professores da UFPE.

\section{REFERÊNCIAS}

BARNETT, Ronald. Los limites de la competencia: el conocimiento, la educación superior y la sociedad. Barcelona: Gedisa, 2001.

BAZZO, Vera Lúcia. Constituição da profissionalidade docente na Educação Superior: desafios e possibilidades. Tese (Doutorado em Educação) Faculdade de Educação, Universidade Federal do Rio Grande do Sul, Porto Alegre, 2007.

BOURDONCLE, Raymond. La professionnalisation des enseignants: analyses sociologiques anglaises et amériaines. Revue Française de Pédagogie, Lyon, n. 94, p. 73-92, 1991.

BOURDONCLE, Raymond; LESSARD, Claude. Qu'est-ce qu'une formation professionnelle universitaire? Conceptions de l'université et formation professionnelle. Revue Française de Pédagogie, Lyon, n. 139, p. 131-154, 2002.

BRAEM, Sophie. Le nécessaire développement théorique de la notion de Profissionannalité pour la Sociologie des Professions française. In: CONFERENCE OF ISA RESEARCH COMMITTEE SOCIOLOGY OF PROFESSIONAL GROUPS RC 52, 2000, Lisboa. Anais. Lisboa: Instituto Superior das Ciências do Trabalho e da Empresa, 2000. 
BROILO, Cecília; CUNHA, Maria Isabel (Org.). Pedagogia universitária e produção de conhecimento.Porto Alegre: EDIPUCRS, 2008. v. 3.

CORDEIRO, Talma; MELO, Márcia (Org.). Formação pedagógica e docência do professor universitário: um debate em construção. Recife: Ed. da UFPE, 2008.

CUNHA, Maria Isabel. O professor universitário na transição de paradigmas. Araraquara: JM, 1998.

CUNHA, Maria Isabel. Trabalho docente e profissionalidade na universidade. Revista de Estudos Curriculares, Porto, v. 4, n. 1, p. 67-84, 2006.

CUNHA, Maria Isabel. O lugar da formação do professor universitário: a condição profissional em questão. In: CUNHA, Maria Isabel (Org.). Reflexóes e práticas em pedagogia universitária. Campinas, SP: Papirus, 2007. p. 11-26.

CUNHA, Maria Isabel; LEITE, Denise. Decisóes pedagógicas e estrutura de poder na universidade. Campinas, SP: Papirus, 1996.

DEMAILLY, Lise. La qualification ou la compétence professionnelle des enseignants. Sociologie du Travail, Paris, v. 29, n. 1, p. 59-69, 1987.

DUBAR, Claude. La qualification à travers les jounées de Nantes. Sociologie du Travail, Paris, v. 29, n. 1, p. 3-14, 1987.

ENGERS, Maria Emília; MOROSINI, Marília (Org.). Pedagogia universitária e aprendizagem. Porto Alegre: EDIPUCRS, 2007. v. 2.

FRANCO, Maria Estela; KRAHE, Elizabeth (Org.). Pedagogia universitária e áreas de conhecimento. Porto Alegre: EDIPUCRS, 2007. v. 1. GAUTHIER, Clemont et al. Por uma teoria da pedagogia: pesquisas contemporâneas sobre o saber docente. Ijuí: Unijuí, 1998.

GIBBONS, Michael et al. The new production of knowledge: the dynamics of science and research in contemporary societies. London: Sage, 1994.

GIMENO SACRISTÁN, José. Consciência e acção sobre a prática como libertação profissional dos professores. In: NÓVOA, António (Org.). Profissáa professor. 2. ed. Porto: Porto, 1995. p. 61-92. 
LEITE, Carlinda (Org.). Sentidos da pedagogia no ensino superior. Porto: CIIE/Livpsic, 2010.

LEITE, Carlinda; RAMOS, Kátia. Docência universitária: análise de uma experiência de formação na Universidade do Porto. In: CUNHA, Maria Isabel Cunha (Org.). Reflexóes e práticas em pedagogia universitária. Campinas, SP: Papirus, 2007. p. 27-42.

RAMALHO, Betania; NUÑEZ, Isauro; GAUTHIER, Clemont. Formar o professor, profissionalizar o ensino: perspectivas e desafios. 2. ed. Porto Alegre: Sulina, 2004.

RAMOS, Kátia. Pedagogia universitária: um olhar sobre um movimento de institucionalização de acções de actualização pedagógico-didáctica como espaço de reflexão sobre a profissionalidade docente universitária. 2008. 361 f. Tese (Doutorado em Ciências da Educação)-Faculdade de Psicologia e de Ciências da Educação, Universidade do Porto, Porto, 2008.

RAMOS, Kátia. Reconfigurar a profissionalidade docente universitária: um olhar sobre açóes de atualização pedagógica-didática. Porto: Ed. da Universidade do Porto, 2010.

RIOS, Terezinha. A dimensão ética da aula ou o que nós fazemos com eles. In: VEIGA, Ilma (Org.). Aula: gênese, dimensões, práticas e princípios. Campinas, SP: Papirus, 2008. p. 73-93.

ROCHA, João. Antes que seja tarde: reflexões sobre o futuro da universidade. In: CASPER, Gerhard; ISER, Wolfgang. Futuro da universidades. Rio de Janeiro: EdUERJ, 2002. p. 15-34.

ROLDÃO, Maria do Céu. Profissionalidade docente em análise: especificidades dos ensinos superior e não superior. Revista NUANCES: Estudos sobre educação, Presidente Prudente, SP, v. 12, n. 13, p. 108126, jan./dez. 2005.

SANTOS, Boaventura Sousa. Pela mão de Alice: o social e o político na pós-modernidade. 5. ed. Porto: Afrontamento, 1996.

SANTOS, Boaventura Sousa. A universidade no século XXI: para uma reforma democrática e emancipatória da universidade. São Paulo: Cortez, 2004. 
TARDIF, Maurice; LESSARD, Claude. O trabalho docente: elementos para uma teoria da docência como profissão de interações humanas. Petrópolis, RJ: Vozes, 2005.

UNIVERSIDADE FEDERAL DE PERNAMBUCO (UFPE). PróReitoria para Assuntos Acadêmicos. Centro de Educação. Departamento de Métodos e Técnicas de Ensino. Projeto de Curso de Atualização Pedagógica para Professores da UFPE. Recife: UFPE, 2000.

UNESCO. Declaración Mundial sobre la Educación Superior en siglo XXI: visión y acción. In: CONFERENCIA MUNDIAL SOBRE LA EDUCACIÓN SUPERIOR, La educación superior en el siglo XXI: visión y acción, 1998, Paris. Disponível em: <http://www.unesco.org/ education/educprog/wche/declaration_spa.htm>. Acesso em: 6 ago. 2006.

VIEIRA, Flávia. Transformar a pedagogia na universidade: narrativas da prática. Santo Tirso: De Facto, 2010.

WITTROCK, Björn. Las tres transformaciones de la universidad moderna. In: ROTHBLATT, Sheldon; WITTROCK, Björn (Org.). La Universidad europea y americana desde 1800: las tres transformaciones de la Universidad. Barcelona: Pomares, 1996. p. 331-394.

ZABALZA, Miguel. $O$ ensino universitário: seu cenário e seus protagonistas. Porto Alegre: Artmed, 2004. 


\section{Questioning knowledge reflecting on action: professors' concerns about the professional quality of university teaching}

\section{Abstract}

This paper is part of the movement to reconsider university teaching and provides elements for the recent debate about the professionalism of university teaching, understanding it as a profession that involves relationships. It gathers data from a decade of involvement in actions to revise pedagogic didactics aimed at university professors, and dialogs with studies based on a perspective with multiple references. The study strives to understand and defend a reflexive, investigative and critical professionalism of university teaching based on individual and collective responsibility. It identifies paths that have allowed university professors to resignify the teaching function, while understanding that to question knowledge and reflect on their actions is inherent to teaching in general and to the dynamics that structure professionalism in university teaching in particular.

Keywords: University teaching professionalism. University teaching. Teacher education.
Inquietudes del profesorado universitario sobre la profesionalidad docente: Cuestionando el conocimiento mediante una reflexión sobre su transmisión

\section{Resumen}

Este trabajo se encuadra dentro del movimiento de reconceptualización de la enseńanza universitaria y tiene como objetivo aportar nuevos elementos al, recientemente abierto, debate sobre la profesionalidad docente en un contexto por el cual ésta es entendida como una profesión de relaciones. Con este fin, se presentan los datos recogidos durante una década de participación en acciones de actualización didáctico-pedagógica dirigidas al profesorado universitario, y se establece un diálogo con un grupo de estudios basados en una mirada multireferencial sobre el entendimiento y la defensa de una profesionalidad docente reflexiva, crítica y basada en una ética de responsabilidad individual y colectiva. En este sentido, se resaltan aquellas vías que han permitido a los profesores universitarios redefinir la labor docente en un contexto de la necesaria asimilación de que cuestionar nuestros propios conocimientos y reflexionar sobre su transmisión resulta, en general, inherente a la profesión docente $y$, en particular, a la dinámica estructuradora de la profesionalidad docente universitaria.

Palabras clave: Profesionalidad Docente Universitaria. Docencia Universitaria. Formación Docente. 


\section{Kátia Maria da Cruz Ramos}

Av. Acadêmico Helio Ramos, s/n, CDU, Recife/PE, CEP 50.670-901 Telefone: (81) 2126.8326

E-mail: katiamcramos@gmail.com

Recebido em: 16/9/2010

Versão final recebida em: 22/10/2011

Aprovado em: 31/10/2011 